\title{
Bone Marrow Adipose Tissue: To Be or Not To Be a Typical Adipose Tissue?
}

\author{
Pierre Hardouin, Tareck Rharass and Stéphanie Lucas* \\ Laboratory of Pathophysiology of Inflammatory Bone Diseases PMOI, University of Littoral-Opale Coast ULCO, \\ Boulogne sur Mer, France
}

\section{OPEN ACCESS}

Edited by:

William Peter Cawthorn,

University of Edinburgh, UK

Reviewed by:

Eleni Douni,

Agricultural University

of Athens, Greece

Ann Schwartz,

University of California

San Francisco, USA

*Correspondence:

Stéphanie Lucas

stephanie.lucas@univ-littoral.fr

Specialty section:

This article was submitted

to Bone Research,

a section of the journal

Frontiers in Endocrinology

Received: 03 May 2016

Accepted: 21 June 2016

Published: 30 June 2016

Citation:

Hardouin $P$, Rharass $T$ and Lucas $S$

(2016) Bone Marrow Adipose

Tissue: To Be or Not To Be a

Typical Adipose Tissue?

Front. Endocrinol. 7:85.

doi: 10.3389/fendo.2016.00085
Bone marrow adipose tissue (BMAT) emerges as a distinct fat depot whose importance has been proved in the bone-fat interaction. Indeed, it is well recognized that adipokines and free fatty acids released by adipocytes can directly or indirectly interfere with cells of bone remodeling or hematopoiesis. In pathological states, such as osteoporosis, each of adipose tissues - subcutaneous white adipose tissue (WAT), visceral WAT, brown adipose tissue (BAT), and BMAT - is differently associated with bone mineral density (BMD) variations. However, compared with the other fat depots, BMAT displays striking features that makes it a substantial actor in bone alterations. BMAT quantity is well associated with BMD loss in aging, menopause, and other metabolic conditions, such as anorexia nervosa. Consequently, BMAT is sensed as a relevant marker of a compromised bone integrity. However, analyses of BMAT development in metabolic diseases (obesity and diabetes) are scarce and should be, thus, more systematically addressed to better apprehend the bone modifications in that pathophysiological contexts. Moreover, bone marrow (BM) adipogenesis occurs throughout the whole life at different rates. Following an ordered spatiotemporal expansion, BMAT has turned to be a heterogeneous fat depot whose adipocytes diverge in their phenotype and their response to stimuli according to their location in bone and BM. In vitro, in vivo, and clinical studies point to a detrimental role of BM adipocytes (BMAs) throughout the release of paracrine factors that modulate osteoblast and/or osteoclast formation and function. However, the anatomical dissemination and the difficulties to access BMAs still hamper our understanding of the relative contribution of BMAT secretions compared with those of peripheral adipose tissues. A further characterization of the phenotype and the functional regulation of BMAs are ever more required. Based on currently available data and comparison with other fat tissues, this review addresses the originality of the BMAT with regard to its development, anatomy, metabolic properties, and response to physiological cues.

Keywords: fat-bone association, marrow fat, adipokine, bone marrow adiposity, skeletal adipocyte, osteoporosis, bone fragility

Besides being the main energy storage sites, adipose tissues have revealed through these last decades their diversity regarding their cellular composition, anatomical location, and pathophysiological properties. Indeed, adipocytes are typically classified into three categories: white, brown, and beige types (1). White adipocytes store excessive energy supply in a unilocular triglyceride droplet to release fatty acids in periods of energy depletion. White adipocytes also exert an endocrine function 
through the secretions of various adipokines that mainly regulate metabolism and inflammation (2). Conversely, brown adipocytes are multilocular, rich in mitochondria, and dissipate the energy into heat through the uncoupling protein-1 (UCP-1). Their high glucose uptake and oxidative capacities make them key players in the energy balance. At last, beige (also called "brite") adipocytes are brown-like adipocytes with UCP-1 expression that arise within white fat depots in response to cold or catecholaminergic stimulation (3).

Most adipose tissues in adult humans consist of white adipose tissue (WAT) that encompasses major subcutaneous depots ( $85 \%$ of total adipose tissue) in the lower or abdominal body parts and visceral fat depots $(\sim 10 \%)$ with omental, mesenteric, or retroperitoneal distributions. According to that anatomical location and the pathophysiological contexts, WATs exhibit differences in their development pattern, lipogenic and lipolytic activities, "browning" ability, or endocrine functions. This is best exemplified by the development of visceral adipose tissue that is considered as a strong predictive factor for the emergence of obesity co-morbidities, notably through the secretion of proinflammatory cytokines and an enhanced lipolysis (4). Brown adipose tissue (BAT) exhibits a more diffuse distribution with discrete small depots. Owing to the recent reassessement of BAT in adults, stimulating BAT and beige adipocyte recruitment have become promising strategies for the management of metabolic diseases $(3,5)$.

In addition to WAT and BAT, bone marrow adipose tissue (BMAT) emerges as a "new" fat depot that could represent up to $5 \%$ of total fat mass in adults. The presence of BMAT - also referred to as "yellow" bone marrow (BM) - was of a long-standing knowledge but has been surprisingly disregarded for many decades. Meanwhile, bone has been revealed as a target and a regulator of energy metabolism: the two main adipokines, adiponectin and leptin, modulate bone mass through indirect and direct mechanisms $(6,7)$ and undercarboxylated osteocalcin, the bone-derived hormone, positively impacts on whole-body glucose metabolism $(8,9)$. Moreover, numerous clinical studies indicate strong relationships between BMAT amount and bone loss emphasizing its potential pathophysiological role in osteoporosis. Other lines of evidence support the involvement of BMAT in hematopoiesis regulation (10) and in the pathophysiology of myeloma (11) and bone metastases (12). Such bone-fat connections have contributed to renew interest in BMAT. Yet, the anatomical dissemination of BM fat and the difficulties to study adipocytes inside bones have considerably hampered our understanding of BM adipocyte (BMA) function and its relative contribution to pathophysiological processes compared with extramedullary fat depots. In this review, we aim at highlighting the current knowledge of BMAT development and phenotype to pinpoint its original features as an adipose tissue.

\section{BMAT DEVELOPMENT IS BOTH PHYSIOLOGICAL AND PATHOLOGICAL}

\section{Exploration of BMAT Development}

The first descriptions of "hematopoietic red BM" replacement by the "fat yellow BM" were brought by histomorphometric studies of iliac crest biopsies in humans $(13,14)$ or other bone sites in animals. BMAT quantification has been, thus, performed using specific but static parameters (adipocyte number and diameter, percent of adipocyte volume per tissue volume), which precludes a reliable and dynamic assessment of adipocyte evolution according to the pathophysiological conditions. Magnetic resonance imaging (MRI) has been being of considerable interest to map non-invasively the distribution of hematopoietic $\mathrm{BM}$ and fatty BM in clinical studies (15). Moreover, proton magnetic resonance spectroscopy (1H MRS) allows the relative assessment of the saturated and unsaturated fatty acid composition of the fat fraction to monitor the lipid content changes. Combined with bone mineral density (BMD) and bone structure measurement by dual energy X-ray absorptiometry (DEXA) and high-resolution peripheral quantitative computed tomography, respectively, MR techniques have been being instrumental to follow BMAT development and to evaluate relationship between bone quantity and BMAT amount in diverse cohorts. Finally, using the lipid affinity of the opaque agent osmium tetroxide, a three-dimensional quantification of BMAT (whole amount, individual volume, spatial distribution) can be achieved by micro- or nanocomputerized tomography ( $\mu \mathrm{CT}$, nanoCT) in animal decalcified bones (16).

\section{Physiological BM Cellular Conversion to BMAT}

Bone marrow adiposity development has been shown to be age, bone site, and gender dependent. At birth, bone cavities mainly contain active hematopoietic red marrow. BMAT accretion then occurs in an orderly and centripetal way: the process begins in the terminal phalanges around birth, continues in the appendicular skeleton (from the diaphysis to the distal and proximal extremities of the long bones) and finally arises in the axial skeleton $(15,17,18)$. By the age of 25 years, BMAT is considered to occupy 50 (17) to $70 \%$ (16) of the BM volume, while hematopoietic BM is mainly restricted to the axial skeleton, ribs, sternum, and proximal metaphyses of humerus and femur. Afterward, the BM conversion into BMAT slowly progresses throughout the adulthood. Interestingly, women exhibit less BMAT amount compared with age-matched men $(19,20)$ prior the menopause age, while the following period is associated with a sharp increase of BM adiposity (21).

The development pattern in rodents is considered to be similar though it is far to be as well characterized as in humans. Histological studies of femur or tibia show the presence of BMA at adult age $(22,23)$, which further increases with aging $(24,25)$. Of note, the percentage of BM adiposity (or BMA density) appears low in rodents when compared with humans and varies according to the mouse strain. Moreover the presence of different BMA subsets could be suspected from early (26) to more recent studies $(27,28)$. However, it is with the new introduction of osmium tetroxide staining combined with $\mu \mathrm{CT}$ visualization that analysis of BMAT development has led to the first characterization of two BMA subpopulations in rodents (29). Scheller and collaborators propose to distinguish constitutive BMA (cBMA) - which arise first and early in life 
in distal tibia and caudal vertebrae to constitute a rather dense fat depot - from regulated BMA (rBMA) whose formation is late, increases with age, and occurs in a more scattered way in the proximal tibia, distal femur, and lumbar vertebrae (29). Importantly, this distinction based on a spatiotemporal distribution also corresponds to a different metabolic pattern and to different bone remodeling regions (see "Specific properties of BMA versus other adipocytes"). How such classification can be extrapolated to humans is still difficult although one can suggest that CBMA reside in the feet and hands, whereas the rBMA develops in the proximal femur and lumbar vertebrae $(16,29)$.

\section{BMAT Development Differs from that of Extramedullary Adipose Tissues}

Formed during gestation, BAT quantity and activity are maximal at birth to provide an efficient thermogenesis during the first weeks. Beyond puberty that is characterized by an important BAT activity, cold-activated BAT incidence remains high in young adults but rapidly declines by the age of 30 to almost disappear in the elderly (30). BAT function and WAT

TABLE 1 | Comparison of the main characteristics of brown adipose tissue (BAT), white adipose tissues (WAT), and bone marrow adipose tissue (BMAT) in rodents.

\begin{tabular}{|c|c|c|c|}
\hline & BAT & WAT & BMAT \\
\hline $\begin{array}{l}\text { Main } \\
\text { locations }\end{array}$ & Interscapular (32) & $\begin{array}{l}\text { Subcutaneous } \\
\text { (inguinal) and visceral } \\
\text { (perigonadal > } \\
\text { mesenteric > } \\
\text { retro-peritoneal) } \\
\text { (32) }\end{array}$ & $\begin{array}{l}\text { Constitutive BMA } \\
\text { (cBMA): distal tibia } \\
\text { and caudal vertebrae } \\
\text { Regulated BMA } \\
\text { (rBMA): proximal } \\
\text { tibia and long bones, } \\
\text { lumbar vertebrae (29) }\end{array}$ \\
\hline $\begin{array}{l}\text { Mean } \\
\text { adipocyte } \\
\text { diameter }\end{array}$ & - & $\begin{array}{l}\text { For rat }{ }^{a} \\
\sim 56 \mu \mathrm{m} \text { for inguinal } \\
\sim 74 \mu \mathrm{m} \text { for } \\
\text { perigonadal }\end{array}$ & $\begin{array}{l}\text { For rat }^{\mathrm{a}} \\
\sim 40 \mu \mathrm{m} \text { for caudal } \\
\text { cBMA } \\
\sim 33 \mu \mathrm{m} \text { for tibia } \\
\text { rBMA }\end{array}$ \\
\hline
\end{tabular}

Amount

variation

during

Aging

$$
\pi \text { with "whitening" }
$$$$
\checkmark \text { activity (33) }
$$

Subcutaneous $\pi$

Visceral $\boldsymbol{\nearrow}$ (33)

入 (mainly rBMA)

$\rightarrow(34,35)$

Calorie

restriction

(30\%)

Cold

exposure

$$
\rightarrow
$$

$\pi$ activity $(36,37)$

Subcutaneous $\mathbf{}$

Visceral $\searrow(34,35)$ or

unchanged (22, 35)

Subcutaneous $\searrow$

with beiging $\pi$

$(36,37)$

High-fat $\quad \boldsymbol{\pi}$ with "whitening" Subcutaneous $\pi$

diet-induced $\searrow$ activity (38)

obesity

Visceral $\pi(39,40)$

Subcutaneous $\pi$

Visceral $\pi(42)$ browning also decrease with age in rodents (31) as shown in Table 1. Thus, the development pattern of BMAT differs from the recruitment of thermogenic adipose tissues during the lifespan and other physiological conditions [exercice, cold exposure $(3,5)]$, supporting that BMAT development responds to different cues.

Early WAT formation is achieved through two early periods of intense precursor proliferation with adipocyte differentiation and lipogenesis in the meanwhile. By the end of adolescence, an adipocyte number set point specific to each individual is considered to be reached and to remain constant throughout life (44), with a rather low adipocyte renewal rate estimated at $8 \%$ per year (45). Indeed, the tremendous expandability of WAT primarily relies on adipocyte hypertrophy (cell size increase). Hyperplasia (cell number increase) occurs secondly when adipocyte storage capacity is exceeded and preferentially in subcutaneous AT. WAT growth is, thus, observed throughout the adult lifespan with a maximal mass achieved at middle-early old age. In advanced old age, white fat depots are redistributed with a subcutaneous fat loss in favor of visceral fat accumulation and ectopic fat deposition in other tissues (46). BMAT development with its long-lasting hyperplasia and concomitant hypertrophy (14) throughout life exhibits some striking differences compared with WAT. Moreover, BMAT amount is generally not correlated to usual anthropometric parameters of adiposity, such as waist-to-hip ratio, amount of visceral or subcutaneous fat, or even body mass index (47-49). Altogether, BMAT formation also appears independently regulated from extramedullary WAT both in humans and rodents (Table $\mathbf{1}$ ).

\section{Adipose Tissues and Relationship with Skeletal Fragility: The Importance of BMAT Development}

Beyond being a simple witness of age, diffuse or local BMAT accumulation has been described in several types of osteoporosis notably that associated with aging, menopause, anorexia nervosa, or glucocorticoid treatment. In humans, BMAT amount is even found inversely correlated with bone quantity in aged $(47,50)$, post-menopausal $(51)$, and anorexia nervosa (52) subjects at various bone sites. Enhanced BMAT formation is also depicted in animal models of aging (53), ovariectomy (27), calorie restriction (22), or following glucocorticoid administration (54). Bone loss results from an altered bone remodeling with either decreased number and/or mineralizing function of osteoblasts as in senile osteoporosis, or with increased bone resorption by osteoclasts that overwhelms bone formation as in post-menopausal osteoporosis (55). BMAT is suspected to contribute to this unbalanced bone remodeling through the adipogenesis process per se or its paracrine activity (see Section "BM Adipogenesis" and "Specific Properties of BMA"). However, it has to be emphasized that blocking BMAT formation failed to generate any bone modification in some mouse models $(56,57)$.

The impact of other adipose tissues on bone has of course been the subject of intensive clinical research that led to a complex picture. Whereas inconsistent results are drawn with subcutaneous adipose tissue measurements, visceral adipose 
tissue level, when directly quantitated, is often found negatively associated with BMD and bone quality (58). Indeed, excess visceral fat as in obesity is paralleled by an altered adipokine secretion with increased pro-inflammatory cytokines that have been suggested to interfere with bone remodeling (59). A positive association between BAT volume and BMD has been reported in a few studies in humans (60-62). Yet the prevalence and activity of BAT in humans remain difficult to measure. The beneficial impact of active BAT on bone has also been reported in mouse models $(63,64)$ and could rely on direct [derived-BAT adipokines (64)] or indirect mechanisms $(61,63)$. Moreover, bone fragility is a comorbidity of several metabolic diseases and BMAT evolution is obviously of interest in that context.

\section{BMAT Development in Metabolic Diseases}

Regarding with type 1 diabetes, genetically or streptozotocininduced insulin deficiency results in increased BMAT in the long bones of mice (65). However, preventing BMAT formation does not impact on the bone loss (66) inherent to these models and the disease. Moreover, as reported in one study, BMAT content measured at different bone sites was unchanged in diabetic patients compared with control subjects (67). Thus, the involvement of BMAT in type 1 diabetes remains unclear and deserves further explorations.

The skeletal health in obesity has been a controversial subject $(68,69)$. However, most clinical and epidemiologic studies have reported an alteration of bone quality in obesity leading to an increased fracture incidence at specific bone sites (59, 70-72). Even though visceral adipose tissue quantity can be negatively associated with bone microarchitecture and strength (73), BMAT content has been poorly examined in obesity. So far, only one clinical study performed in obese premenopausal women has reported a positive correlation between visceral adiposity and vertebral BMAT (74). The Ob/Ob mouse model with extreme obesity due to spontaneous leptin disruption shows increased $\mathrm{BM}$ adipogenesis in the long bones (75). Nevertheless, this model remains complex to analyze because of the pleiotropic effects of leptin on bone and metabolism. The BMA amount in the long bones also increases in models of high-fat diet-induced obesity $(39,41,76)$ (Table 1). However, divergent results make it difficult to conclude about the bone phenotype in these models and no associations have been drawn between metabolic parameters and the BMAT rise yet. Of note, animal age and diet duration appear to influence BMAT increment $(41,76)$, so that older mice would develop more quickly and at a higher level BMA.

Type 2 diabetic patients exhibit an increased fracture risk that is predominantly linked to a compromised bone quality $(77,78)$. In post-menopausal women, BMAT content in vertebrae is found unchanged by the diabetic state $(79,80)$, even though it is higher in patients who experienced prolonged hyperglycemia reflected by a HbA1c level above 7\% (79).

Weight loss is well known to trigger bone loss, as exemplified in anorexia nervosa but also in bariatric surgery in obesity care (59). In anorexia nervosa (52), BMAT unexpectedly develops while subcutaneous and essentially visceral adipose tissues are extremely depleted. Bariatric surgery (81) or a 4-week-calorie restriction (82) in obese women leads to a marked or a more modest reduction of extramedullary fat depots, respectively. Yet, these decreases are not accompanied by significant changes in BMAT volume. These later studies rely on a limited number of subjects but suggest that the initial metabolic status [diabetes (81) or abdominal adipose tissue distribution (82)] can impact on the BMAT amount changes.

In summary, compared with other fat depots, BMAT could, thus, be considered as a strong and reliable indicator of bone integrity that could open new clinical perspectives in the management of osteoporosis (83). Its measurement rather easily performed using MRI should be more systematically analyzed particularly in metabolic diseases considering that most available data have been generated in animal models. In response to metabolic variations, BMAT development differs from other fat depots in both humans and rodents. Yet, it remains conceivable that BMAT expansion may not be completely independent from the WAT distribution. In this connection, BMAT accretion could be triggered when WAT redistribution occurs as in aging. However, the paradoxical situation of anorexia nervosa supports that BMAT formation is dissociated from that of other fat tissues. A mechanistic pathway shared by all physiopathological conditions to explain BMAT development is, thus, still missing.

\section{BM Adipogenesis}

Bone marrow adipogenesis of resident mesenchymal stem cell (MSC) is classically controlled through a transcriptional cascade involving the key transcriptional factors PPAR $\gamma$ and $\mathrm{c} / \mathrm{EBP} \alpha$. Within the BM, MSCs reside in the perivascular compartment, at the endosteal surface, and in the marrow space. As in other tissues, BM MSCs represent a heterogeneous cell population with regard to their cell surface marker expression and differentiation potential toward the osteoblast, adipocyte, or chondrocyte lineages $(84,85)$. It has to be emphasized that a great diversity of adipocyte precursors (distinct MSC populations, pericyte progenitors) for WAT and BAT has been revealed and debated this last decade $(3,44,86)$. Interestingly, whereas most adipocytes also develop from adipose tissue-resident progenitors, engrafted BM-derived cells have been shown to generate new adipocytes within WAT in both humans (87) and rodents (88), which argues for another interaction between BM and WAT.

Importantly, adipogenesis is well considered as a competitive process for osteoblastogenesis within the BM. Haplo-insufficiency or overexpression of PPAR $\gamma$ in BM progenitor cells results in increased osteoblastogenesis or adipogenesis, respectively (89). Both in vitro and in vivo studies have shown that various conditions - such as elevated glucocorticoid levels, estrogen withdrawal, oxidative stress, and immobilization - that promote adipogenesis limit osteoblastogenesis. Conversely, pro-osteogenic factors [growth hormone, insulin-like growth factor 1 (IGF1), Wnt proteins, estrogens, mechanic inputs] decrease adipogenesis $(85,89$, 90). Thus, the BM MSC shift toward either lineage results from a complex interplay of systemic and local mediators.

However, the classical view of an unbalanced adipogenesis at the expense of osteoblastogenesis is challenged by other findings. 
The coexistence within the mouse BM of independent precursor cells committed to each lineage has been shown (91). Both adipocytes and osteoblasts can fully develop from mouse BM MSC in a co-differentiation medium without any alteration of either lineage (92). As described in Section "Physiological BM Cellular Conversion to BMAT," a part of BMAT development occurs when the bone mass peak is achieved at human puberty and cBMA fully arise without bone loss in rodents. Bone mass can evolve independently of BM adipogenesis in some models $(56,57)$ or mouse strain (e.g., the $\mathrm{C} 3 \mathrm{H} / \mathrm{HeJ}$ strain) (93).

In this context, BMAT development cannot represent the only detrimental mechanism. BMA phenotype - which underlies its function - should be considered as a pivotal aspect in bone alterations as emphasized below.

\section{SPECIFIC PROPERTIES OF BMA VERSUS OTHER ADIPOCYTES}

\section{Basic Anatomy of the "BMAT"}

Compared with subcutaneous or visceral fat lobules composed of $\sim 80 \%$ well-packed adipocytes, BMAs arise loosely connected and scattered among hematopoietic cells. In that respect, such adipocyte distribution may not be referred to as a true "adipose tissue”. Whereas cBMA constitute a rather dense adipocyte area, rBMA are primarily located at the trabecular site where bone remodeling is active, which suggests their involvement in this process. The sympathetic cue is crucial in bone homeostasis (94) but the nerve distribution toward BMAs has not been depicted yet. Compared with hematopoietic areas, BMA-enriched regions are considered to be less vascularized with a lower perfusion as observed in the hip of normal-aged subjects (95). Moreover, vascularization could differ between cBMA and rBMA areas with, surprisingly, a higher capillary density in the cBMA regions in mouse (96).

Bone marrow adipocytes appear filled by a large unilocular lipid vacuole, a typical morphology of white adipocytes. Human BMA diameter can vary from 40 to $65 \mu \mathrm{m}$ according to the fat infiltration (14), the cellular composition of BM (97), or the analyzed age $(14,98)$. BMAs are, thus, smaller than subcutaneous and visceral adipocytes in both humans and rodents, with cBMA larger than rBMA (Table 1).

\section{A White or Brown/Beige Phenotype?}

Determining the white or brown/brite phenotype of BMA is crucial with regard to a better understanding of their regulation and function. The development factors (Table 1) and the unilocular morphology of BMAs are more reminiscent of a white adipocyte. However, the preferential distribution of BM adiposity in the appendicular skeleton following a temperature gradient led some authors to propose a thermogenic role for the adipocytes $(99,100)$. Several gene markers specific for the "brown/beige" lineage were found expressed in the whole tibia BM in young mice. Based on the expression of both white and brown markers upon rosiglitazone treatment, although UCP-1 expression was barely detected, the authors proposed that BMAT has the two phenotypes (101). A high glucose uptake detected within the BM of cold-exposed patients combined with the immuno-detection of UCP-1 protein in the BMA of very young mice convincingly support the potential presence of functional brown/beige BMA in vertebrae (102). However, these results are contradicted by other studies. Several genes of the fatty acid oxidation pathway were found more weakly expressed in isolated BMA from long bones in comparison with isolated visceral adipocytes in mouse (23). Similarly, human BMA isolated from the iliac crest had lower mRNA levels of typical markers of the brown phenotype compared with subcutaneous adipocytes (103). Importantly, a long-term cold exposure of mice led to a marked decline of BMA density in tibiae but a concomitant browning of other WAT depots (29). Altogether, one may suggest that the BMA phenotype varies according to their localization: BMAs that arise in the long bones most likely belong to the white lineage, whereas some BMAs in the vertebrae can exhibit brown-like features. The presence of such thermogenic adipocytes could explain the disappearance of the "yellow BM" in the caudal vertebrae during a temperature rise (104). Indeed, hematopoiesis remains quite efficient in the vertebra BM and brown adipocytes have been proposed to support myelopoiesis through the secretion of some specific adipokines (102).

Most studies characterizing BMA have been performed from long bones or iliac crest samples and have raised some puzzling specificities regarding their paracrine/endocrine and metabolic properties.

\section{Secretory Profile of BMA}

The two main adipokines adiponectin and leptin are detected in isolated mature BMA, could locally promote osteoblastogenesis, and impact on osteoclastogenesis or hematopoiesis (89). However, their mRNA expression levels were found markedly low compared with extramedullary adipocytes in adult healthy donors (103) and normal-aged mice (23).This finding may relate to a lower state of differentiation of BMA as proposed in aging mice (23). Yet BMAT explants from rabbit (distal tibia) or human patients (tibia) were shown to secrete more adiponectin than other WAT depots. Moreover, through the characterization of a mouse model of defective BM adipogenesis, BMAT was revealed as a significant source of serum adiponectin during caloric restriction (34). Even though this contribution to the calorie restriction-induced adiponectinemia rise was not confirmed in rabbits (35), this study underlies a true endocrine status of BMA which can modulate metabolism at the systemic level.

Given the importance of inflammatory factors in the bone loss of post-menopause or aging, the cytokine production by BMA has begun to be assessed. A first antibody-based array study indicates that the cytokine content of BMA diverges from that of subcutaneous adipocytes with a more pro-adipogenic and proapoptotic profile in aging mice (105). In another independent transcriptomic study in mice, BMAs were reported to express inflammatory genes, such as TNF $\alpha$ and IL6, at higher levels than visceral adipocytes (23). Surprisingly, in both studies, their expression levels were downregulated during aging, suggesting 
that this pro-inflammatory profile of BMA is rather early and transient. Of note, another transcriptional analysis failed to detect any further upregulation of these genes in the BMA from normalaged mice fed with a high-fat diet (24). Interestingly, primary human femoral BMAs express the pro-osteoclastogenic factor RANKL and mediate through a direct cell contact the differentiation of osteoclast precursors $(106,107)$. RANKL expression was also shown to be associated with BMA differentiation and with Pref1-expressing preadipocytes in the BM of aging mice (108).

Several in vitro studies using notably co-culture models $(109,110)$ of BM MSC-derived adipocytes and osteoblasts strongly support a deleterious paracrine role of BMA. BM MSCderived adipocytes have also been reported to secrete factors that alter osteoblastogenesis and favor adipogenesis, such as Wnt signaling inhibitors (111) and chemerin (112) (Figure 1).

\section{Metabolic Profile of BMA}

Adipocytes synthesize and hydrolyze triglycerides in response to insulin and catecholamines, the respective prototypical lipogenic and lipolytic factors. Functional assays to establish the relative capacity of BMA for lipogenesis and lipolysis compared with other fat depots remain scarce due to technical difficulties. Only one early study in rabbits has reported that isolated femoral adipocytes incorporate palmitate into triglycerides at level equivalent to perirenal adipocytes (113).
Catecholamine-induced lipolysis appeared lower in femur compared with omental adipose tissue in dogs (114). More indirectly, but in line with their small size, mouse BMAs were shown to express weaker expression of key genes involved in lipogenesis and lipolysis compared with visceral adipocytes (23). Moreover, the metabolic activity of BMA has been indirectly assessed by the adipocyte size and density determination and seems to vary according to their bone localization and the different subtypes in rodents. Indeed, only BMA in the lumbar spine were affected by a chronic administration of a $\beta 3$-adrenergic agonist (27). In the tibia, cBMA were reported resistant to a long-term cold-induced catecholamine challenge compared with the regulated subpopulation (29). Whether these observations result from the development timing of each BMA subset, a different innervation/vascularization of the BM regions or intrinsic divergences among BMA subtypes has to be further explored. Nevertheless, the relative amount of BMAT compared with other adipose tissues supports that the metabolic influence of BMA is locally confined.

Importantly, the fatty acid composition of BMA is emerging as a key signature of their phenotype. Compared with subcutaneous adipose tissue, lipid extracts of human BM (mainly from proximal tibia or femur) display a higher proportion of saturated fatty acids and a lower amount of monounsaturated ones (115). Based on $1 \mathrm{H}$ MRS exploration, the unsaturation index of the

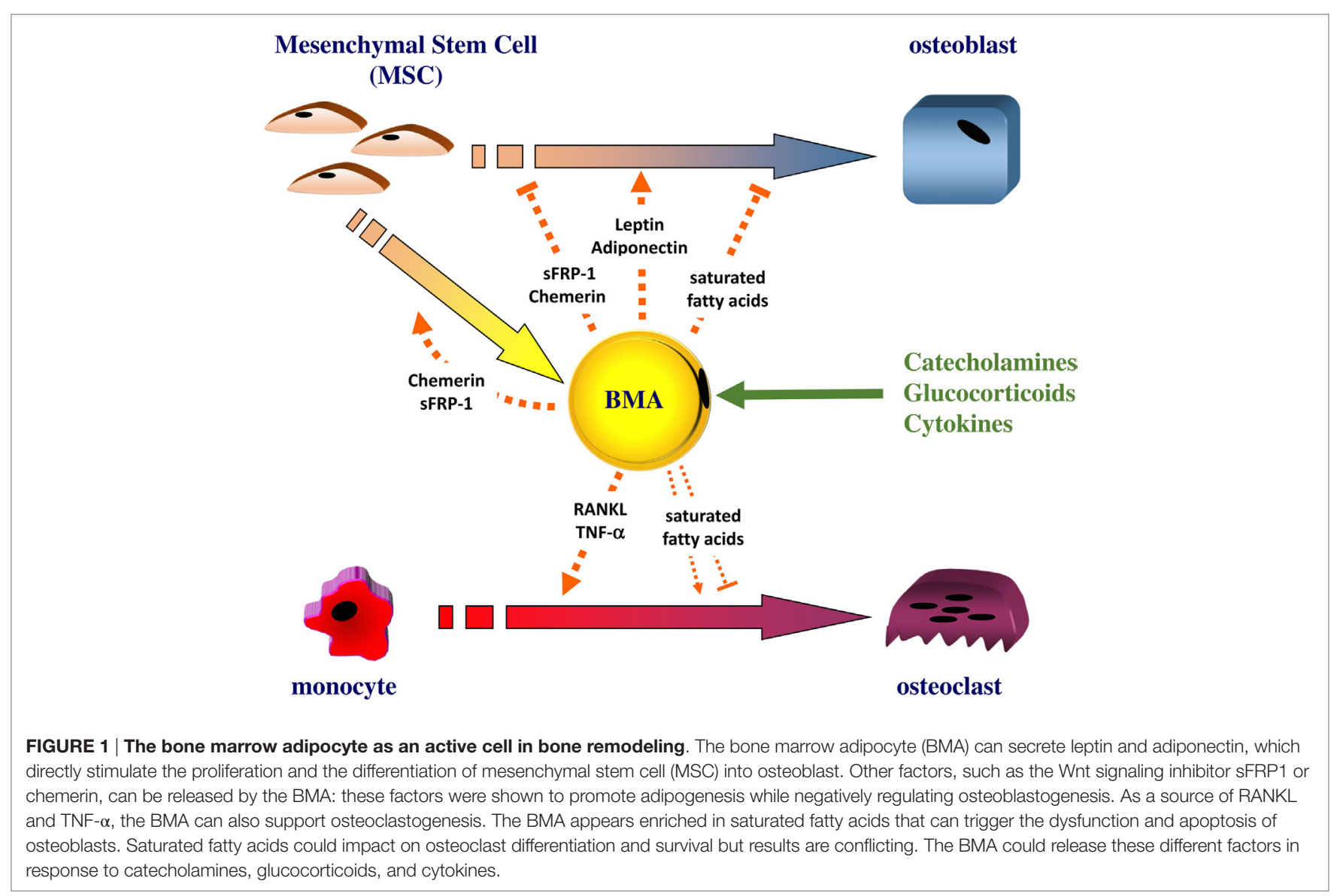


vertebral fat fraction is decreased compared with controls and inversely associated with bone loss (51) or fragility fractures (80) in post-menopausal women. Moreover, in healthy adult women, a gradual increase of the unsaturation index is observed from the proximal femur to the most distal part of the tibia, suggesting a differential fatty acid distribution in the BMA subpopulations. Accordingly, this was further examined in several bone sites in rats to reveal a higher unsaturation index in cBMA compared with regulated ones (29). These studies strongly support that BMA associated with bone alterations preferentially store saturated fatty acids. This has a strong pathophysiological relevance since in vitro chronic exposure of osteoblasts to saturated fatty acids triggers their dysfunction and apoptosis (116-118). Results are conflicting for the resorbing cells since saturated fatty acids were reported either to reduce osteoclastogenesis (119) or to exert beneficial effects on mature osteoclasts by preventing their apoptosis (120). Though the amount of fatty acids released by BMA appears rather low in vitro (121), BMA could contribute to bone alterations through a detrimental fatty acid-mediated process referred as lipotoxicity. Moreover, a specific lipid pattern of BMA may be considered as a discriminative trait, which is rather puzzling considering that dietary fat intake usually impacts on the fatty acid composition of bone (122), adipose tissues, and blood (123). The variation in the BMA fatty acid content could reflect an adaptation to systemic metabolic alterations $(79,80)$ and/or an intrinsic characteristic through the expression of desaturases (29).

\section{Regulation of BMA Function}

Directly assessing the factors regulating the BMA function as done through ex vivo experiments with other fat depots is hampered by the dissemination and the scarcity of BMAT in animal models. Alternatively, indirect measurements of BMA activity through the size and density determination have often been performed using long-term experimentations $(27,29,40)$. However, in such studies $(27,40)$, experiments are often carried out while $\mathrm{BM}$ adipogenesis is also initiated, which may interfere with the interpretation of the mature BMA response. One may propose to perform tests when BM adiposity (and mostly rBMA) is fully developed: indeed, a few interventional studies have already uncovered for example a sensitivity to estradiol for BMAT in post-menopausal women $(124,125)$ or to growth hormone for tibial rBMA in dwarf rats (126). Moreover, using radiolabeled glucose or fatty acid analogs with Positron Emission Tomography imaging could be helpful to decipher the metabolic function and regulation of BMA during acute challenges. So far, information regarding the regulation of BMA function mainly comes from in vitro studies (Figure 1).

As mentioned before, like for other WAT, catecholamines or agonists of the $\beta$-adrenergic receptors stimulate fatty acid release from BMA both in vitro $(121,127,128)$ and in vivo (114). Surprisingly, insulin addition does not seem necessary for human BM MSC adipogenesis and subsequent lipogenesis in vitro $(109,127,129)$. However, insulin acutely stimulates glucose uptake (130) and modifies the adipokine pattern $(127,131)$ in vitro and in organotypic cultures supporting that BMAs are sensitive to insulin.
Dexamethasone triggers lipolysis (118) and stimulates the secretion of leptin from human BM MSC-derived adipocytes (118) or human primary cultivated BMAs (131) like reported for extramedullary white adipocytes. Regarding to adiponectin secretion, discrepancies are obtained according to the studied model $(118,131)$. Dexamethasone also stimulates the expression of RANKL in human primary BMAs (106).

Similarly to white adipocytes, cytokines - including notably $\mathrm{TNF} \alpha$ - alter leptin secretion in two cultured models $(131,132)$, supporting that BMAs are also sensitive to a pro-inflammatory environment.

\section{CONCLUSION}

Bone marrow adipose tissue is metabolically distinct from other fat depots as indicated by several evidence related to its development and properties. Numerous data from clinical studies, in vivo, and vitro models point to an involvement of BMAT in bone remodeling resulting in bone alterations. Besides the participation of the adipogenesis process, BMAs are active cells whose phenotype is strikingly heterogeneous according to the bone site or BM area. Compared with cBMA, rBMA appear highly responsive to diverse stimuli. The first characterizations of BMA as well as their sensitivity to catecholamines and glucocorticoids support that BMA behaves more as a white-like adipocyte whose fatty acid or adipokine release could impact on BM cells (Figure 1). Moreover, its phenotype could also evolve when bone remodeling is altered. Owing to its specific microenvironment, it is expected that osteoblasts, osteoclasts, hematopoietic, and other bone cells reciprocally regulate $\mathrm{BMA}$ function. In that respect, a description of BMAT vascularization, innervation, and interaction with BM cells is needed to better comprehend its regulation. Moreover, the relative contribution of BMAT secretions compared with those of extramedullary adipose tissues remains poorly examined, which emphasizes the necessity to deepen the characterization of BMA. So far considering the different physiopathological situations of BMAT development together has not led to a shared hypothesis defining the role of BMA. This actually suggests that, as a true responsive cell, BMA function and regulation could vary according to the pathophysiological context and should be analyzed accordingly.

\section{AUTHOR CONTRIBUTIONS}

SL drafted the review. TR and SL made the figure. PH, TR, and SL contributed to the design of the review, critically revised it, approved the final version to be published, and agreed to be accountable for all aspects of the work.

\section{ACKNOWLEDGMENT}

Writing of this review was enabled by ULCO University.

\section{FUNDING}

The study was supported by ULCO University and The French Society of Rhumatology (SFR). 


\section{REFERENCES}

1. Rosen ED, Spiegelman BM. What we talk about when we talk about fat. Cell (2014) 156:20-44. doi:10.1016/j.cell.2013.12.012

2. Fasshauer M, Blüher M. Adipokines in health and disease. Trends Pharmacol Sci (2015) 36:461-70. doi:10.1016/j.tips.2015.04.014

3. Peirce V, Carobbio S, Vidal-Puig A. The different shades of fat. Nature (2014) 510:76-83. doi:10.1038/nature13477

4. White UA, Tchoukalova YD. Sex dimorphism and depot differences in adipose tissue function. Biochim Biophys Acta (2014) 1842:377-92. doi:10.1016/j. bbadis.2013.05.006

5. Peng X-R, Gennemark P, O'Mahony G, Bartesaghi S. Unlock the thermogenic potential of adipose tissue: pharmacological modulation and implications for treatment of diabetes and obesity. Front Endocrinol (2015) 6:174. doi:10.3389/ fendo.2015.00174

6. Kawai M, de Paula FJA, Rosen CJ. New insights into osteoporosis: the bone-fat connection. J Intern Med (2012) 272:317-29. doi:10.1111/j.13652796.2012.02564.x

7. Naot D, Cornish J. Cytokines and hormones that contribute to the positive association between fat and bone. Front Endocrinol (2014) 5:70. doi:10.3389/ fendo.2014.00070

8. Karsenty G, Ferron M. The contribution of bone to whole-organism physiology. Nature (2012) 481:314-20. doi:10.1038/nature10763

9. Wei J, Karsenty G. An overview of the metabolic functions of osteocalcin. Rev Endocr Metab Disord (2015) 16:93-8. doi:10.1007/s11154-014-9307-7

10. Bianco P, Robey PG. Skeletal stem cells. Development (2015) 142:1023-7. doi:10.1242/dev.102210

11. Reagan MR, Liaw L, Rosen CJ, Ghobrial IM. Dynamic interplay between bone and multiple myeloma: emerging roles of the osteoblast. Bone (2015) 75:161-9. doi:10.1016/j.bone.2015.02.021

12. Hardaway AL, Herroon MK, Rajagurubandara E, Podgorski I. Bone marrow fat: linking adipocyte-induced inflammation with skeletal metastases. Cancer Metastasis Rev (2014) 33:527-43. doi:10.1007/s10555-013-9484-y

13. Meunier P, Aaron J, Edouard C, Vignon G. Osteoporosis and the replacement of cell populations of the marrow by adipose tissue. A quantitative study of 84 iliac bone biopsies. Clin Orthop (1971) 80:147-54. doi:10.1097/ 00003086-197110000-00021

14. Rozman C, Feliu E, Berga L, Reverter JC, Climent C, Ferrán MJ. Age-related variations of fat tissue fraction in normal human bone marrow depend both on size and number of adipocytes: a stereological study. Exp Hematol (1989) 17:34-7.

15. Hwang S, Panicek DM. Magnetic resonance imaging of bone marrow in oncology, part 1. Skeletal Radiol (2007) 36:913-20. doi:10.1007/s00256007-0309-3

16. Scheller EL, Troiano N, Vanhoutan JN, Bouxsein MA, Fretz JA, Xi Y, et al. Use of osmium tetroxide staining with microcomputerized tomography to visualize and quantify bone marrow adipose tissue in vivo. Methods Enzymol (2014) 537:123-39. doi:10.1016/B978-0-12-411619-1.00007-0

17. Blebea JS, Houseni M, Torigian DA, Fan C, Mavi A, Zhuge Y, et al. Structural and functional imaging of normal bone marrow and evaluation of its age-related changes. Semin Nucl Med (2007) 37:185-94. doi:10.1053/j. semnuclmed.2007.01.002

18. Scheller EL, Rosen CJ. What's the matter with MAT? Marrow adipose tissue, metabolism, and skeletal health: marrow adipose tissue and skeletal health. Ann N Y Acad Sci (2014) 1311:14-30. doi:10.1111/nyas.12327

19. Kugel H, Jung C, Schulte O, Heindel W. Age- and sex-specific differences in the $1 \mathrm{H}$-spectrum of vertebral bone marrow. J Magn Reson Imaging (2001) 13: 263-8. doi:10.1002/1522-2586(200102)13:2<263::AID-JMRI1038>3.3.CO;2-D

20. Pansini V, Monnet A, Salleron J, Hardouin P, Cortet B, Cotten A. 3 Tesla (1) H MR spectroscopy of hip bone marrow in a healthy population, assessment of normal fat content values and influence of age and sex. JMagn Reson Imaging (2014) 39:369-76. doi:10.1002/jmri.24176

21. Griffith JF, Yeung DKW, Ma HT, Leung JCS, Kwok TCY, Leung PC. Bone marrow fat content in the elderly: a reversal of sex difference seen in younger subjects. J Magn Reson Imaging (2012) 36:225-30. doi:10.1002/jmri.23619

22. Devlin MJ, Cloutier AM, Thomas NA, Panus DA, Lotinun S, Pinz I, et al. Caloric restriction leads to high marrow adiposity and low bone mass in growing mice. J Bone Miner Res (2010) 25:2078-88. doi:10.1002/jbmr.82
23. Liu L-F, Shen W-J, Ueno M, Patel S, Kraemer FB. Characterization of agerelated gene expression profiling in bone marrow and epididymal adipocytes. BMC Genomics (2011) 12:212. doi:10.1186/1471-2164-12-212

24. Liu L-F, Shen W-J, Ueno M, Patel S, Azhar S, Kraemer FB. Age-related modulation of the effects of obesity on gene expression profiles of mouse bone marrow and epididymal adipocytes. PLoS One (2013) 8:e72367. doi:10.1371/ journal.pone.0072367

25. Lazarenko OP, Rzonca SO, Hogue WR, Swain FL, Suva LJ, Lecka-Czernik B. Rosiglitazone induces decreases in bone mass and strength that are reminiscent of aged bone. Endocrinology (2007) 148:2669-80. doi:10.1210/en. 2006-1587

26. Tavassoli M, Crosby WH. Bone marrow histogenesis: a comparison of fatty and red marrow. Science (1970) 169:291-3. doi:10.1126/science.169.3942.291

27. Kurabayashi T, Tomita M, Matsushita H, Honda A, Takakuwa K, Tanaka K. Effects of a beta 3 adrenergic receptor agonist on bone and bone marrow adipocytes in the tibia and lumbar spine of the ovariectomized rat. Calcif Tissue Int (2001) 68:248-54. doi:10.1007/s002230001203

28. Devlin M, Vliet MV, Motyl K, Karim L, Brooks D, Louis L, et al. Early onset type 2 diabetes impairs skeletal acquisition in the male TALLYHO/JngJ mouse. Endocrinology (2014) 155:3806-16. doi:10.1210/en.2014-1041

29. Scheller EL, Doucette CR, Learman BS, Cawthorn WP, Khandaker S, Schell B, et al. Region-specific variation in the properties of skeletal adipocytes reveals regulated and constitutive marrow adipose tissues. Nat Commun (2015) 6:7808. doi:10.1038/ncomms 8808

30. Rogers NH. Brown adipose tissue during puberty and with aging. Ann Med (2015) 47:142-9. doi:10.3109/07853890.2014.914807

31. Graja A, Schulz TJ. Mechanisms of aging-related impairment of brown adipocyte development and function. Gerontology (2015) 61:211-7. doi: $10.1159 / 000366557$

32. Waldén TB, Hansen IR, Timmons JA, Cannon B, Nedergaard J. Recruited vs. nonrecruited molecular signatures of brown, "brite," and white adipose tissues. Am J Physiol Endocrinol Metab (2012) 302:E19-31. doi:10.1152/ ajpendo.00249.2011

33. Sellayah D, Sikder D. Orexin restores aging-related brown adipose tissue dysfunction in male mice. Endocrinology (2014) 155:485-501. doi:10.1210/ en.2013-1629

34. Cawthorn WP, Scheller EL, Learman BS, Parlee SD, Simon BR, Mori H, et al. Bone marrow adipose tissue is an endocrine organ that contributes to increased circulating adiponectin during caloric restriction. Cell Metab (2014) 20:368-75. doi:10.1016/j.cmet.2014.06.003

35. Cawthorn WP, Scheller EL, Parlee SD, Pham HA, Learman BS, Redshaw CMH, et al. Expansion of bone marrow adipose tissue during caloric restriction is associated with increased circulating glucocorticoids and not with hypoleptinemia. Endocrinology (2016) 157:508-21. doi:10.1210/en.2015-1477

36. Lim S, Honek J, Xue Y, Seki T, Cao Z, Andersson P, et al. Cold-induced activation of brown adipose tissue and adipose angiogenesis in mice. Nat Protoc (2012) 7:606-15. doi:10.1038/nprot.2012.013

37. Hao Q, Yadav R, Basse AL, Petersen S, Sonne SB, Rasmussen S, et al. Transcriptome profiling of brown adipose tissue during cold exposure reveals extensive regulation of glucose metabolism. Am J Physiol Endocrinol Metab (2015) 308:E380-92. doi:10.1152/ajpendo.00277.2014

38. Shimizu I, Aprahamian T, Kikuchi R, Shimizu A, Papanicolaou KN, MacLauchlan S, et al. Vascular rarefaction mediates whitening of brown fat in obesity. J Clin Invest (2014) 124:2099-112. doi:10.1172/JCI71643

39. Halade GV, Rahman MM, Williams PJ, Fernandes G. High fat diet-induced animal model of age-associated obesity and osteoporosis. J Nutr Biochem (2010) 21:1162-9. doi:10.1016/j.jnutbio.2009.10.002

40. Styner M, Thompson WR, Galior K, Uzer G, Wu X, Kadari S, et al. Bone marrow fat accumulation accelerated by high fat diet is suppressed by exercise. Bone (2014) 64C:39-46. doi:10.1016/j.bone.2014.03.044

41. Shu L, Beier E, Sheu T, Zhang H, Zuscik MJ, Puzas EJ, et al. High-fat diet causes bone loss in young mice by promoting osteoclastogenesis through alteration of the bone marrow environment. Calcif Tissue Int (2015) 96(4):313-23. doi:10.1007/s00223-015-9954-Z

42. Nadal-Casellas A, Proenza AM, Lladó I, Gianotti M. Effects of ovariectomy and 17- $\beta$ estradiol replacement on rat brown adipose tissue mitochondrial function. Steroids (2011) 76:1051-6. doi:10.1016/j.steroids.2011.04.009 
43. de Heredia FP, Larque E, Portillo MDP, Canteras M, Zamora S, Garaulet M. Age-related changes in fatty acids from different adipose depots in rat and their association with adiposity and insulin. Nutrition (2008) 24:1013-22. doi:10.1016/j.nut.2008.03.022

44. Berry R, Jeffery E, Rodeheffer MS. Weighing in on adipocyte precursors. Cell Metab (2014) 19:8-20. doi:10.1016/j.cmet.2013.10.003

45. Spalding KL, Arner E, Westermark PO, Bernard S, Buchholz BA, Bergmann O, et al. Dynamics of fat cell turnover in humans. Nature (2008) 453:783-7. doi:10.1038/nature06902

46. Cartwright MJ, Tchkonia T, Kirkland JL. Aging in adipocytes: potential impact of inherent, depot-specific mechanisms. Exp Gerontol (2007) 42:463-71. doi:10.1016/j.exger.2007.03.003

47. Justesen J, Stenderup K, Ebbesen EN, Mosekilde L, Steiniche T, Kassem $M$. Adipocyte tissue volume in bone marrow is increased with aging and in patients with osteoporosis. Biogerontology (2001) 2:165-71. doi:10.102 3/A:1011513223894

48. Shen W, Chen J, Punyanitya M, Shapses S, Heshka S, Heymsfield SB. MRImeasured bone marrow adipose tissue is inversely related to DXA-measured bone mineral in Caucasian women. Osteoporos Int (2007) 18:641-7. doi:10.1007/s00198-006-0285-9

49. Di Iorgi N, Rosol M, Mittelman SD, Gilsanz V. Reciprocal relation between marrow adiposity and the amount of bone in the axial and appendicular skeleton of young adults. J Clin Endocrinol Metab (2008) 93:2281-6. doi:10.1210/ jc.2007-2691

50. Griffith JF, Yeung DKW, Antonio GE, Lee FKH, Hong AWL, Wong SYS, et al. Vertebral bone mineral density, marrow perfusion, and fat content in healthy men and men with osteoporosis: dynamic contrast-enhanced MR imaging and MR spectroscopy. Radiology (2005) 236:945-51. doi:10.1148/ radiol.2363041425

51. Yeung DKW, Griffith JF, Antonio GE, Lee FKH, Woo J, Leung PC. Osteoporosis is associated with increased marrow fat content and decreased marrow fat unsaturation: a proton MR spectroscopy study. J Magn Reson Imaging (2005) 22:279-85. doi:10.1002/jmri.20367

52. Bredella MA, Fazeli PK, Miller KK, Misra M, Torriani M, Thomas BJ, et al. Increased bone marrow fat in anorexia nervosa. JClin Endocrinol Metab (2009) 94:2129-36. doi:10.1210/jc.2008-2532

53. Kajkenova O, Lecka-Czernik B, Gubrij I, Hauser SP, Takahashi K, Parfitt AM, et al. Increased adipogenesis and myelopoiesis in the bone marrow of SAMP6, a murine model of defective osteoblastogenesis and low turnover osteopenia. J Bone Miner Res (1997) 12:1772-9. doi:10.1359/jbmr.1997.12.11.1772

54. Li G-W, Xu Z, Chen Q-W, Chang S-X, Tian Y-N, Fan J-Z. The temporal characterization of marrow lipids and adipocytes in a rabbit model of glucocorticoid-induced osteoporosis. Skeletal Radiol (2013) 42:1235-44. doi:10.1007/s00256-013-1659-7

55. Marie PJ, Kassem M. Extrinsic mechanisms involved in age-related defective bone formation. JClin Endocrinol Metab (2011) 96:600-9. doi:10.1210/ jc. $2010-2113$

56. Justesen J, Mosekilde L, Holmes M, Stenderup K, Gasser J, Mullins JJ, et al. Mice deficient in 11beta-hydroxysteroid dehydrogenase type 1 lack bone marrow adipocytes, but maintain normal bone formation. Endocrinology (2004) 145:1916-25. doi:10.1210/en.2003-1427

57. Iwaniec UT, Turner RT. Failure to generate bone marrow adipocytes does not protect mice from ovariectomy-induced osteopenia. Bone (2013) 53:145-53. doi:10.1016/j.bone.2012.11.034

58. Sheu Y, Cauley JA. The role of bone marrow and visceral fat on bone metabolism. Curr Osteoporos Rep (2011) 9:67-75. doi:10.1007/s11914-011-0051-6

59. Shapses SA, Sukumar D. Bone metabolism in obesity and weight loss. Annu Rev Nutr (2012) 32:287-309. doi:10.1146/annurev.nutr.012809.104655

60. Bredella MA, Fazeli PK, Freedman LM, Calder G, Lee H, Rosen CJ, et al. Young women with cold-activated brown adipose tissue have higher bone mineral density and lower pref- 1 than women without brown adipose tissue: a study in women with anorexia nervosa, women recovered from anorexia nervosa, and normal-weight women. JClin Endocrinol Metab (2012) 97:E584-90. doi:10.1210/jc.2011-2246

61. Ponrartana S, Aggabao PC, Hu HH, Aldrovandi GM, Wren TAL, Gilsanz V. Brown adipose tissue and its relationship to bone structure in pediatric patients. J Clin Endocrinol Metab (2012) 97:2693-8. doi:10.1210/ jc.2012-1589
62. Lee P, Brychta RJ, Collins MT, Linderman J, Smith S, Herscovitch P, et al. Cold-activated brown adipose tissue is an independent predictor of higher bone mineral density in women. Osteoporos Int (2013) 24:1513-8. doi:10.1007/s00198-012-2110-y

63. Motyl KJ, Bishop KA, DeMambro VE, Bornstein SA, Le P, Kawai M, et al. Altered thermogenesis and impaired bone remodeling in misty mice. J Bone Miner Res (2013) 28:1885-97. doi:10.1002/jbmr.1943

64. Rahman S, Lu Y, Czernik PJ, Rosen CJ, Enerback S, Lecka-Czernik B. Inducible brown adipose tissue, or beige fat, is anabolic for the skeleton. Endocrinology (2013) 154:2687-701. doi:10.1210/en.2012-2162

65. Botolin S, McCabe LR. Bone loss and increased bone adiposity in spontaneous and pharmacologically induced diabetic mice. Endocrinology (2007) 148:198-205. doi:10.1210/en.2006-1006

66. Botolin S, McCabe LR. Inhibition of PPAR $\gamma$ prevents type I diabetic bone marrow adiposity but not bone loss. J Cell Physiol (2006) 209:967-76. doi:10.1002/jcp. 20804

67. Slade JM, Coe LM, Meyer RA, McCabe LR. Human bone marrow adiposity is linked with serum lipid levels not T1-diabetes. J Diabetes Complications (2012) 26:1-9. doi:10.1016/j.jdiacomp.2011.11.001

68. Reid IR. Fat and bone. Arch Biochem Biophys (2010) 503:20-7. doi:10.1016/j. abb.2010.06.027

69. Johansson H, Kanis JA, Odén A, McCloskey E, Chapurlat RD, Christiansen $\mathrm{C}$, et al. A meta-analysis of the association of fracture risk and body mass index in women. J Bone Miner Res (2014) 29:223-33. doi:10.1002/jbmr.2017

70. Compston JE, Watts NB, Chapurlat R, Cooper C, Boonen S, Greenspan S, et al. Obesity is not protective against fracture in postmenopausal women: GLOW. Am J Med (2011) 124:1043-50. doi:10.1016/j.amjmed.2011.06.013

71. Prieto-Alhambra D, Premaor MO, Fina Avilés F, Hermosilla E, MartinezLaguna D, Carbonell-Abella C, et al. The association between fracture and obesity is site-dependent: a population-based study in postmenopausal women. J Bone Miner Res (2012) 27:294-300. doi:10.1002/jbmr.1466

72. Premaor MO, Compston JE, Fina Avilés F, Pagès-Castellà A, Nogués X, Díez-Pérez A, et al. The association between fracture site and obesity in men: a population-based cohort study. J Bone Miner Res (2013) 28:1771-7. doi:10.1002/jbmr.1878

73. Bredella MA, Lin E, Gerweck AV, Landa MG, Thomas BJ, Torriani M, et al. Determinants of bone microarchitecture and mechanical properties in obese men. JClin Endocrinol Metab (2012) 97:4115-22. doi:10.1210/ jc.2012-2246

74. Bredella MA, Torriani M, Ghomi RH, Thomas BJ, Brick DJ, Gerweck AV, et al. Vertebral bone marrow fat is positively associated with visceral fat and inversely associated with IGF-1 in obese women. Obesity (Silver Spring) (2011) 19:49-53. doi:10.1038/oby.2010.106

75. Hamrick MW, Pennington C, Newton D, Xie D, Isales C. Leptin deficiency produces contrasting phenotypes in bones of the limb and spine. Bone (2004) 34:376-83. doi:10.1016/j.bone.2003.11.020

76. Doucette CR, Horowitz MC, Berry R, MacDougald OA, Anunciado-Koza R, Koza RA, et al. High fat diet increases bone marrow adipose tissue (MAT) but does not alter trabecular or cortical bone mass in C57BL/6J mice. J Cell Physiol (2015) 230:2032-7. doi:10.1002/jcp.24954

77. Dede AD, Tournis S, Dontas I, Trovas G. Type 2 diabetes mellitus and fracture risk. Metabolism (2014) 63:1480-90. doi:10.1016/j.metabol.2014.09.002

78. Saito M, Marumo K. Bone quality in diabetes. Front Endocrinol (2013) 4:72. doi:10.3389/fendo.2013.00072

79. Baum T, Yap SP, Karampinos DC, Nardo L, Kuo D, Burghardt AJ, et al. Does vertebral bone marrow fat content correlate with abdominal adipose tissue, lumbar spine bone mineral density, and blood biomarkers in women with type 2 diabetes mellitus? J Magn Reson Imaging (2012) 35:117-24. doi:10.1002/jmri.22757

80. Patsch JM, Li X, Baum T, Yap SP, Karampinos DC, Schwartz AV, et al. Bone marrow fat composition as a novel imaging biomarker in postmenopausal women with prevalent fragility fractures. J Bone Miner Res (2013) 28:1721-8. doi: $10.1002 / j \mathrm{jmr} .1950$

81. Schafer AL, Li X, Schwartz AV, Tufts LS, Wheeler AL, Grunfeld C, et al. Changes in vertebral bone marrow fat and bone mass after gastric bypass surgery: a pilot study. Bone (2015) 74:140-5. doi:10.1016/j.bone.2015.01.010

82. Cordes C, Dieckmeyer M, Ott B, Shen J, Ruschke S, Settles M, et al. MR-detected changes in liver fat, abdominal fat, and vertebral bone marrow 
fat after a four-week calorie restriction in obese women. JMagn Reson Imaging (2015) 42:1272-80. doi:10.1002/jmri.24908

83. Paccou J, Hardouin P, Cotten A, Penel G, Cortet B. The role of bone marrow fat in skeletal health: usefulness and perspectives for clinicians. JClin Endocrinol Metab (2015) 100:3613-21. doi:10.1210/jc.2015-2338

84. Sivasubramaniyan K, Lehnen D, Ghazanfari R, Sobiesiak M, Harichandan A, Mortha E, et al. Phenotypic and functional heterogeneity of human bone marrow- and amnion-derived MSC subsets. Ann N Y Acad Sci (2012) 1266:94-106. doi:10.1111/j.1749-6632.2012.06551.x

85. Abdallah BM, Kassem M. New factors controlling the balance between osteoblastogenesis and adipogenesis. Bone (2012) 50:540-5. doi:10.1016/j. bone.2011.06.030

86. Ma X, Lee P, Chisholm DJ, James DE. Control of adipocyte differentiation in different fat depots; implications for pathophysiology or therapy. Front Endocrinol (2015) 6:1. doi:10.3389/fendo.2015.00001

87. Rydén $M$, Uzunel $M$, Hård JL, Borgström E, Mold JE, Arner E, et al. Transplanted bone marrow-derived cells contribute to human adipogenesis. Cell Metab (2015) 22:408-17. doi:10.1016/j.cmet.2015.06.011

88. Crossno JT, Majka SM, Grazia T, Gill RG, Klemm DJ. Rosiglitazone promotes development of a novel adipocyte population from bone marrow-derived circulating progenitor cells. J Clin Invest (2006) 116:3220-8. doi:10.1172/ JCI28510

89. Sadie-Van Gijsen H, Crowther NJ, Hough FS, Ferris WF. The interrelationship between bone and fat: from cellular see-saw to endocrine reciprocity. Cell Mol Life Sci (2013) 70:2331-49. doi:10.1007/s00018-012-1211-2

90. Nuttall ME, Shah F, Singh V, Thomas-Porch C, Frazier T, Gimble JM. Adipocytes and the regulation of bone remodeling: a balancing act. Calcif Tissue Int (2014) 94:78-87. doi:10.1007/s00223-013-9807-6

91. Post S, Abdallah BM, Bentzon JF, Kassem M. Demonstration of the presence of independent pre-osteoblastic and pre-adipocytic cell populations in bone marrow-derived mesenchymal stem cells. Bone (2008) 43:32-9. doi:10.1016/j. bone.2008.03.011

92. Ghali O, Broux O, Falgayrac G, Haren N, van Leeuwen JPTM, Penel G, et al. Dexamethasone in osteogenic medium strongly induces adipocyte differentiation of mouse bone marrow stromal cells and increases osteoblast differentiation. BMC Cell Biol (2015) 16:9. doi:10.1186/s12860-015-0056-6

93. Fazeli PK, Horowitz MC, MacDougald OA, Scheller EL, Rodeheffer MS, Rosen CJ, et al. Marrow fat and bone - new perspectives. J Clin Endocrinol Metab (2013) 98:935-45. doi:10.1210/jc.2012-3634

94. Karsenty G, Oury F. The central regulation of bone mass, the first link between bone remodeling and energy metabolism. J Clin Endocrinol Metab (2010) 95:4795-801. doi:10.1210/jc.2010-1030

95. Budzik J-F, Lefebvre G, Forzy G, El Rafei M, Chechin D, Cotten A. Study of proximal femoral bone perfusion with 3D T1 dynamic contrast-enhanced MRI: a feasibility study. Eur Radiol (2014) 24:3217-23. doi:10.1007/ s00330-014-3340-5

96. Roche B, David V, Vanden-Bossche A, Peyrin F, Malaval L, Vico L, et al. Structure and quantification of microvascularisation within mouse long bones: what and how should we measure? Bone (2012) 50:390-9. doi:10.1016/j.bone.2011.09.051

97. Abella E, Feliu E, Granada I, Millá F, Oriol A, Ribera JM, et al. Bone marrow changes in anorexia nervosa are correlated with the amount of weight loss and not with other clinical findings. Am J Clin Pathol (2002) 118:582-8. doi:10.1309/2Y7X-YDXK-006B-XLT2

98. Allen JE, Henshaw DL, Keitch PA, Fews AP, Eatough JP. Fat cells in red bone marrow of human rib: their size and spatial distribution with respect to the radon-derived dose to the haemopoietic tissue. Int J Radiat Biol (1995) 68:669-78. doi:10.1080/09553009514551681

99. Gimble JM, Nuttall ME. Bone and fat: old questions, new insights. Endocrine (2004) 23:183-8. doi:10.1385/ENDO:23:2-3:183

100. Lecka-Czernik B. Marrow fat metabolism is linked to the systemic energy metabolism. Bone (2012) 50:534-9. doi:10.1016/j.bone.2011.06.032

101. Krings A, Rahman S, Huang S, Lu Y, Czernik PJ, Lecka-Czernik B. Bone marrow fat has brown adipose tissue characteristics, which are attenuated with aging and diabetes. Bone (2012) 50:546-52. doi:10.1016/j.bone.2011.06.016

102. Nishio M, Yoneshiro T, Nakahara M, Suzuki S, Saeki K, Hasegawa M, et al. Production of functional classical brown adipocytes from human pluripotent stem cells using specific hemopoietin cocktail without gene transfer. Cell Metab (2012) 16:394-406. doi:10.1016/j.cmet.2012.08.001
103. Poloni A, Maurizi G, Serrani F, Mancini S, Zingaretti MC, Frontini A, et al. Molecular and functional characterization of human bone marrow adipocytes. Exp Hematol (2013) 41:558-66.e2. doi:10.1016/j.exphem. 2013.02.005

104. Huggins C, Blocksom BH. Changes in outlying bone marrow accompanying a local increase of temperature within physiological limits. J Exp Med (1936) 64:253-74. doi:10.1084/jem.64.2.253

105. Gasparrini M, Rivas D, Elbaz A, Duque G. Differential expression of cytokines in subcutaneous and marrow fat of aging C57BL/6J mice. Exp Gerontol (2009) 44:613-8. doi:10.1016/j.exger.2009.05.009

106. Goto H, Osaki M, Fukushima T, Sakamoto K, Hozumi A, Baba H, et al. Human bone marrow adipocytes support dexamethasone-induced osteoclast differentiation and function through RANKL expression. Biomed Res (2011) 32:37-44. doi:10.2220/biomedres.32.37

107. Goto H, Hozumi A, Osaki M, Fukushima T, Sakamoto K, Yonekura A, et al. Primary human bone marrow adipocytes support TNF- $\alpha$-induced osteoclast differentiation and function through RANKL expression. Cytokine (2011) 56:662-8. doi:10.1016/j.cyto.2011.09.005

108. Takeshita S, Fumoto T, Naoe Y, Ikeda K. Age-related marrow adipogenesis is linked to increased expression of RANKL. J Biol Chem (2014) 289:16699-710. doi:10.1074/jbc.M114.547919

109. Clabaut A, Delplace S, Chauveau C, Hardouin P, Broux O. Human osteoblasts derived from mesenchymal stem cells express adipogenic markers upon coculture with bone marrow adipocytes. Differentiation (2010) 80:40-5. doi:10.1016/j.diff.2010.04.004

110. Zhang H, Lu W, Zhao Y, Rong P, Cao R, Gu W, et al. Adipocytes derived from human bone marrow mesenchymal stem cells exert inhibitory effects on osteoblastogenesis. Curr Mol Med (2011) 11:489-502. doi:10.2174/ 156652411796268704

111. Taipaleenmäki H, Abdallah BM, AlDahmash A, Säämänen A-M, Kassem M. Wnt signalling mediates the cross-talk between bone marrow derived pre-adipocytic and pre-osteoblastic cell populations. Exp Cell Res (2011) 317:745-56. doi:10.1016/j.yexcr.2010.12.015

112. Muruganandan S, Roman AA, Sinal CJ. Role of chemerin/CMKLR1 signaling in adipogenesis and osteoblastogenesis of bone marrow stem cells. J Bone Miner Res (2010) 25:222-34. doi:10.1359/jbmr.091106

113. Trubowitz S, Bathija A. Cell size and plamitate-1-14c turnover of rabbit marrow fat. Blood (1977) 49:599-605.

114. Tran MA, Dang TL, Berlan M. Effects of catecholamines on free fatty acid release from bone marrow adipose tissue. J Lipid Res (1981) 22:1271-6.

115. Griffith JF, Yeung DKW, Ahuja AT, Choy CWY, Mei WY, Lam SSL, et al. A study of bone marrow and subcutaneous fatty acid composition in subjects of varying bone mineral density. Bone (2009) 44:1092-6. doi:10.1016/j. bone.2009.02.022

116. Elbaz A, Wu X, Rivas D, Gimble JM, Duque G. Inhibition of fatty acid biosynthesis prevents adipocyte lipotoxicity on human osteoblasts in vitro. J Cell Mol Med (2010) 14:982-91. doi:10.1111/j.1582-4934.2009.00751.x

117. Gunaratnam K, Vidal C, Gimble JM, Duque G. Mechanisms of palmitate-induced lipotoxicity in human osteoblasts. Endocrinology (2014) 155:108-16. doi:10.1210/en.2013-1712

118. Wang D, Haile A, Jones LC. Dexamethasone-induced lipolysis increases the adverse effect of adipocytes on osteoblasts using cells derived from human mesenchymal stem cells. Bone (2013) 53:520-30. doi:10.1016/j. bone.2013.01.009

119. Cornish J, MacGibbon A, Lin J-M, Watson M, Callon KE, Tong PC, et al. Modulation of osteoclastogenesis by fatty acids. Endocrinology (2008) 149:5688-95. doi:10.1210/en.2008-0111

120. Oh S-R, Sul O-J, Kim Y-Y, Kim H-J, Yu R, Suh J-H, et al. Saturated fatty acids enhance osteoclast survival. J Lipid Res (2010) 51:892-9. doi:10.1194/ jlr.M800626

121. Lucas S, Clabaut A, Ghali O, Haren N, Hardouin P, Broux O. Implication of fatty acids in the inhibitory effect of human adipocytes on osteoblastic differentiation. Bone (2013) 55:429-30. doi:10.1016/j.bone.2013.04.010

122. During A, Penel G, Hardouin P. Understanding the local actions of lipids in bone physiology. Prog Lipid Res (2015) 59:126-46. doi:10.1016/j. plipres.2015.06.002

123. Hodson L, Skeaff CM, Fielding BA. Fatty acid composition of adipose tissue and blood in humans and its use as a biomarker of dietary intake. Prog Lipid Res (2008) 47:348-80. doi:10.1016/j.plipres.2008.03.003 
124. Syed FA, Oursler MJ, Hefferan TE, Peterson JM, Riggs BL, Khosla S. Effects of estrogen therapy on bone marrow adipocytes in postmenopausal osteoporotic women. Osteoporos Int (2008) 19:1323-30. doi:10.1007/s00198008-0574-6

125. Limonard EJ, Veldhuis-Vlug AG, van Dussen L, Runge JH, Tanck MW, Endert E, et al. Short-term effect of estrogen on human bone marrow fat. J Bone Miner Res (2015) 30:2058-66. doi:10.1002/jbmr.2557

126. Gevers EF, Loveridge N, Robinson ICAF. Bone marrow adipocytes: a neglected target tissue for growth hormone. Endocrinology (2002) 143:406573. doi:10.1210/en.2002-220428

127. Laharrague P, Larrouy D, Fontanilles AM, Truel N, Campfield A, Tenenbaum $\mathrm{R}$, et al. High expression of leptin by human bone marrow adipocytes in primary culture. FASEB J (1998) 12:747-52.

128. Dicker A, Le Blanc K, Aström G, van Harmelen V, Götherström C, Blomqvist $\mathrm{L}$, et al. Functional studies of mesenchymal stem cells derived from adult human adipose tissue. Exp Cell Res (2005) 308:283-90. doi:10.1016/j. yexcr.2005.04.029

129. Zhao X-Y, Chen X-Y, Zhang Z-J, Kang Y, Liao W-M, Yu W-H, et al. Expression patterns of transcription factor PPAR $\gamma$ and C/EBP family members during in vitro adipogenesis of human bone marrow mesenchymal stem cells. Cell Biol Int (2015) 39:457-65. doi:10.1002/cbin.10415
130. Franchini M, Monnais E, Seboek D, Radimerski T, Zini E, Kaufmann K, et al. Insulin resistance and increased lipolysis in bone marrow derived adipocytes stimulated with agonists of toll-like receptors. Horm Metab Res (2010) 42:703-9. doi:10.1055/s-0030-1261872

131. Uchihashi K, Aoki S, Shigematsu M, Kamochi N, Sonoda E, Soejima H, et al. Organotypic culture of human bone marrow adipose tissue. Pathol Int (2010) 60:259-67. doi:10.1111/j.1440-1827.2010.02511.x

132. Laharrague P, Truel N, Fontanilles AM, Corberand JX, Pénicaud L, Casteilla L. Regulation by cytokines of leptin expression in human bone marrow adipocytes. Horm Metab Res (2000) 32:381-5. doi:10.1055/s-2007-978658

Conflict of Interest Statement: The authors declare that the research was conducted in the absence of any commercial or financial relationships that could be construed as a potential conflict of interest.

Copyright (C) 2016 Hardouin, Rharass and Lucas. This is an open-access article distributed under the terms of the Creative Commons Attribution License (CC BY). The use, distribution or reproduction in other forums is permitted, provided the original author(s) or licensor are credited and that the original publication in this journal is cited, in accordance with accepted academic practice. No use, distribution or reproduction is permitted which does not comply with these terms. 